\title{
SHORTNOTE
}

\section{THE IMPACT OF GLUE-LINES ON THE PROTECTIVE EFFECT OF A LOW- PULSED ELECTRIC FIELD IN WOOD}

\author{
Andreas Treu, Erik Larnøy \\ Norwegian Institute of Bioeconomy Research \\ NORWAY \\ (Received November 20i9)
}

\begin{abstract}
A wood protection method using electric fields to inhibit wood decay by brown rot fungi has been investigated in laboratory trials. Glued and non-glued wood samples were exposed to fungal attack for 6 weeks in Petri dishes and showed significantly reduced mass loss when connected to a low pulsed electric field (LPEF). The mass loss of LPEF-protected samples was in average lower than $10 \%$, with a wood moisture content above $40 \%$. The mass loss of untreated wood samples was above $30 \%$ in average. The glue line did not represent a barrier for the electric field in the test setup (a), where the glue line was applied on the transverse section of two glue-jointed wood sample halves. A test setup with two glue lines at the tangential side of three jointed wood samples, showed only slightly higher mass loss compared with wood samples consisting of two jointed halves. It is concluded that glue lines using the MUF glue mix used in this study do not impede the protective effect of LPEF.
\end{abstract}

KEYWORDS: Fungal attack, glue line, low pulsed electric field, wood decay, wood protection.

\section{INTRODUCTION}

The efficacy of a low-pulsed electric field (LPEF) as a wood protection method has been investigated both against decay fungi and surface fungi (Starck and Treu 2013, Treu 2013, Treu et al. 2014, Treu and Larnøy 2016). Little is known on the mode of action, the effect on material moisture content, or the degree of protection provided when applied to larger samples such as glue-laminated wood. One research question related to the use of LPEF on glue-laminated wood is the influence of the glue line on the protective effect of LPEF.

The aim of this study was to analyze the influence of melamine urea formaldehyde (MUF) glue lines in two different test setups on the efficacy of a low-pulsed electric field (LPEF) on wood samples exposed to brown-rot in fungal trials. The specific objective was to evaluate the mass loss and wood moisture content after exposure to the test fungus. 


\section{MATERIALS AND METHODS}

\section{Wood material}

Unleached Scots pine (Pinus sylvestris) sapwood samples from eastern Norway with dimensions of $30 \times 10 \times 5 \mathrm{~mm}$ were used in a decay laboratory test in accordance with Bravery (1978). Two different types of glued wood samples were produced: samples glued together with their transverse section (test setup (a) and (c)) and sandwich samples where 3 samples were glued together on their tangential surface (test setup (e) and (f)).

Samples connected with LPEF had a $5 \mathrm{~mm}$ deep and $2.1 \mathrm{~mm}$ diameter hole on both transverse sections, where electrodes were placed. All wood samples were sterilized including the already installed electric cabling by exposure to $25-50 \mathrm{kGy} \gamma$-radiation using a 60Co source prior to fungal exposure. An overview over wood samples and the test setups is given in Tab. 1.

\section{Electrode material}

Metal-free conductive solid polymer (Elektroplast AS), $45 \mathrm{~mm}$ in length and $2 \times 2 \mathrm{~mm}$ in lateral dimensions, was used to connect LPEF to the wood samples. The polymer was used to avoid corrosion and leaching of copper from the cables. Conductive polymer was inserted into each hole in the cross sections of the wood and connected to splices and insulated copper cables, which were connected to the LPEF generator. Sterile cables (EKKX copper signal cable, $\varnothing=0.5 \mathrm{~mm}$ ) were introduced into the Petri dishes through small holes in the lid, which were wax-sealed afterwards.

\section{Fungi}

The brown rot fungus Coniophora puteana (Schumacher ex Fries), Karsten, strain (BAM Ebw. 15) was used as test basidiomycete, which is an obligatory fungus, when testing according to CEN EN 113 (1996). Petri dishes contained $25 \mathrm{ml}$ 4\% (w/v) malt agar. A plastic mesh was used to avoid direct contact between the samples and the medium. After 6 weeks of incubation period, fungal mycelium was removed from the wood samples, which were dried at $103^{\circ} \mathrm{C}$, and mass loss (\%) was calculated.

\section{Adhesive}

A melamine urea formaldehyde (MUF) adhesive system was used (MUF Prefere $4547+$ hardener 5047) to glue the wood as shown in Tab. 1. The MUF was mixed together with the hardener in a glue mix of 100:100 $\mathrm{m} / \mathrm{m}$ and spread one-sided on the transverse section of the wood samples (test setup (a) and (c)) and on the tangential side of the wood sample (test setup (e) and (f)).

\section{Electric fields}

The electric field used in this study was permanently connected to the wood material (in test setup (a), (b) and (e) during the test period. A low-intensity and low-frequency $(0.806 \mathrm{~Hz})$ pulsed electrical current was used as described by Treu and Larnøy (2016).

\section{Statistical analysis}

Analysis of variance and Tukey-Kramer HSD tests were performed by JMP Pro software version 14.0 in order to analyze the differences in mass loss and wood moisture content after fungal exposure. Mean mass loss values without common letters are significantly different according to Tukey Kramer HSD test on a significance level of $\alpha=0.05$. 
Vol. 65 (4): 2020

Tab. 1: Overview of test setups.

\begin{tabular}{|c|c|c|c|}
\hline $\begin{array}{l}\text { Test } \\
\text { setup }\end{array}$ & Description & Test design & $\begin{array}{l}\text { Number of } \\
\text { Petri dishes }\end{array}$ \\
\hline a & $\begin{array}{l}\text { Two glued wood samples per Petri dish. One control } \\
\text { wood sample and one sample connected to LPEF. }\end{array}$ & & 6 \\
\hline $\mathrm{b}$ & $\begin{array}{l}\text { Two non-glued wood samples per Petri dish. One } \\
\text { control wood sample and one sample connected to } \\
\text { LPEF. }\end{array}$ & & 6 \\
\hline c & $\begin{array}{l}\text { Two wood samples per Petri dish. One glued wood } \\
\text { sample and one control sample. }\end{array}$ & & 6 \\
\hline d & Two untreated control samples per Petri dish. & & 3 \\
\hline $\mathrm{e}$ & $\begin{array}{l}\text { Two tangentially glued wood sandwich samples per } \\
\text { Petri dish. One wood sandwich sample connected to } \\
\text { LPEF in the middle sample and one wood sandwich } \\
\text { sample as control. }\end{array}$ & & 6 \\
\hline $\mathrm{f}$ & $\begin{array}{l}\text { One tangentially glued wood sandwich samples and one } \\
\text { control wood sample per Petri dish. }\end{array}$ & & 6 \\
\hline
\end{tabular}

\section{RESULTS AND DISCUSSION}

\section{Protection of wood by LPEF}

The mass loss of LPEF-connected wood samples was in average lower than $10 \%$ (Fig. 1) and was significantly lower compared with the mass loss of control samples in test setup (a) and (b) on a level of $\mathrm{P}<0.0001$. However, there was no significant difference of LPEF-connected sandwich samples and their controls in test setup (e). 


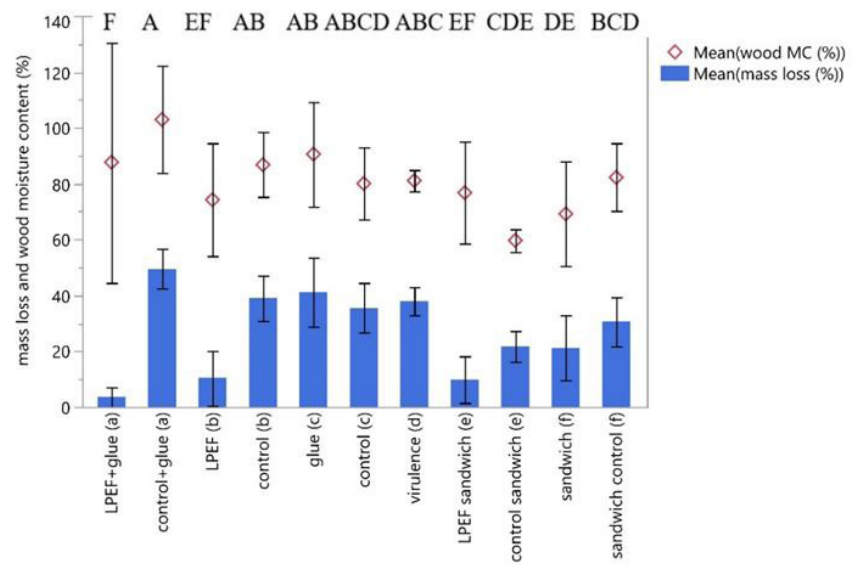

Fig. 1: Mass loss and moisture content (MC) of LPEF-connected and unconnected wood samples after 6 weeks of exposure to brown rot decay.

The mass loss was slightly higher in LPEF-connected samples of setup (b) compared with mass loss in earlier reported studies (Treu 2013) and higher compared with mass loss from glued samples in setup a (LPEF+ glue (a)). Other studies, using the same miniaturised wood-block test showed $<3 \%$ mass loss after eight weeks of incubation time for leached and copper-based wood preservative-treated Scots pine samples, while untreated controls showed around 50\% mass loss (Temiz et al. 2014).

The LPEF-connected sandwich in test (e) showed lower mass loss compared to the sandwich control samples and comparable to the mass loss of LPEF-connected samples in test (b). However, the difference in mass loss was not significant. Since the three single wood samples, which formed one sandwich could not been separated after the decay test without damage, the dry weight of each single part of the sandwich after decay testing could not be determined accurately. It is therefore uncertain to which extend LPEF could protect the individual wood samples glued together to form the sandwich.

\section{The role of wood moisture content}

The wood moisture content (MC) of all exposed wood samples exceeded $40 \%$ and created a favorable environment for fungal growth (Fig. 1). Wood moisture content in test setup (a) showed large variation and some samples exceeded the maximum MC (80\%) of optimal fungal growth according to the standard.

The fungi contributed to elevate MC due to fungal activity or growth of hyphae (Schmidt 2006). Wood moisture content kept below $20 \%$ is considered to protect from basidiomycete decay (Dix and Webster 1995). The brown rot fungus Coniophora puteana was not able to degrade pine wood below 29\% MC in a pile test (Meyer et al. 206).

The dielectric properties of wood are dependent on wood moisture content. Above 20\% wood moisture content, the dielectric constant increases and becomes dependent on the frequency in microwave range (Torgovnikov 1993). Increasing free water in the wood will further reduce the isolating properties of wood. In addition to water, the relationship between frequency and electrical conductivity, as well as wood anatomical factors and wood species need to be considered (Husein et al. 2014). In addition to free water in the wood, conductive ions produced by the fungi, 
play an important role in the conductive properties of wood (Xu et al. 2019). The wood moisture content in our test has been favorable for both decay fungi and electric conductivity. Initial wood decay could have a positive effect on conductivity and could even have increased the effect of LPEF in this study.

\section{Influence of glue lines on the protective effect of LPEF}

The influence of a glue line in wood samples is presumably low, based on the results of test setup (a). However, it is likely that the two glue lines at the tangential side of the sandwich samples of test setup (e) contribute slightly to hindering the protective effect of LPEF. Different adhesive types showed an influence on the decay resistance in laminated veneer lumber of oak (Reinprecht et al. 2010) and is assumed to impact the effectiveness of LPEF as well. Further investigations need to include other adhesive systems in combination with various glue line thicknesses.

\section{CONCLUSIONS}

Our study found a protective effect of a low pulsed electric field (LPEF) on glued and non-glued wood samples, when exposed to basidiomycetes in laboratory fungal trials. The different setups showed less than 10\% mass loss when LPEF was connected, while the mass loss of untreated controls was above $30 \%$. The glue lines applied in our test setup did not impede the protective effect of LPEF. Wood moisture content was generally high in wood samples from all test setups (> 40\%).

Wood moisture content and electric conductivity of the wood material during the test coincided in the way that the wood samples were susceptible to fungal attack and the conductivity was high enough for LPEF to hinder decay of the wood samples. The frequency and the voltage are expected to be too low to induce a heating effect of wood and can therefore not be used to explain the mode of action. Glue line thickness and adhesive type would have an impact on the test results and should be investigated.

\section{ACKNOWLEDGMENTS}

The authors would like to thank the financial support of the NMBU Technology Transfer Office (NMBU TTO).

\section{REFERENCES}

1. Bravery, A.F., 1978: A miniaturised wood-block test for the rapid evaluation of wood preservative fungicides. The International Research Group on Wood Preservation, Peebles, Scotland, IRG/WP 78-2113.

2. CEN EN 113, 1996: Wood preservatives. Test method for determining the protective effectiveness against wood destroying basidiomycetes. Determination of the toxic values.

3. Dix, N.J., Webster, J., 1995: Fungal ecology. Springer Science \& Business Media, Chapman \& Hall, London, 548 pp.

4. Husein, I., Sadiyo, S., Agustina, A., 2014: Electrical properties of Indonesian hardwood case study: Acacia mangium, Swietenia macrophylla and Maesopsis eminii. Wood Research 59(4): 695-704. 
5. Meyer, L., Brischke, C., Treu, A., Larsson-Brelid, P., 2016: Critical moisture conditions for fungal decay of modified wood by basidiomycetes as detected by pile tests. Holzforschung 70(4): 331-339.

6. Reinprecht, L., Svoradova, M., Reh, R., Marchal, R., Charrier, B., 2010: Decay resistance of laminated veneer Lumbers from European oaks. Wood Research 55(4): 79-90.

7. Schmidt, O., 2006: Wood and tree fungi. Biology, damage, protection and use. Springer Verlag, Berlin Heidelberg, 334 pp.

8. Starck, M., Treu, A., 2013: Influence of a pulsed electric field on the growth of surface fungi. The international Research Group on wood Protection, Stockholm, Sweden, IRG/ WP 13-10795.

9. Temiz A., Alfredsen G., Yildiz U.C., Gezer E.D., Kose G., Akbas S., Yildiz, S., 2014: Leaching and decay resistance of alder and pine wood treated with copper based wood preservatives. Maderas-Ciencia y Tecnologia 16(1): 63-76.

10. Torgovnikov, G., 1993: Dielectric properties of wood and wood-based materials (ed). Springer Series in Wood Science. Springer-Verlag, Berlin, Heidelberg, New York, 196 pp.

11. Treu, A., 2013: Holzschutz mit Hilfe von Elektropuls. Holztechnologie 54: 27-31.

12. Treu, A., Bardage, S., Johansson, M., Trey, S., 2014: Fungal durability of polyaniline modified wood and the impact of a low pulsed electric field. International Biodeterioration \& Biodegradation 87: 26-33.

13. Treu, A., Larnøy, E., 2016: Impact of a low pulsed electric field on the fungal degradation of wood in laboratory trials. International Biodeterioration \& Biodegradation 114: 244-251.

14. Xu, H., Li, Q. Xu, Q. Bao, Z., Wang, L., Xing, T., 2019: Effects of brown-rot decay on the electrical resistance of wood and its mechanism. Bioresources 14(3): 6134-6145.

\author{
Andreas Treu*, Erik Larnøy \\ Norwegian Institute of Bioeconomy Research \\ Department Wood Technology \\ Рв. II5, I43I Ås \\ Norway \\ *Corresponding author: andreas.treu@nibio.no
}

